\title{
粶 \\ REINTERPRETAR SEMPRE E OS HORIZONTES DA HISTÓRIA
}

\section{PEDRO PINCHAS GEIGER ${ }^{1}$}

Resumo: Linguagem e vocabulário se modificam, elas acompanham as transições dos modos de produção. A maior compreensão dos desenvolvimentos históricos de tempos idos muito profundos se realiza através da re-interpretação dos conceitos de antigos vocábulos. Principalmente, quando estas re-interpretações podem ser alinhados com descobertas arqueológicas, seguindo o princípio de que "é o presente que explica o passado". Neste trabalho é realizado um "estudo de caso", tendo como objeto passagens escritas em Hebraico de uma "grande narrativa", o Livro do Gênesis, suposto como sendo uma coletânea de memórias orais provenientes dos mais profundos tempos.

Frases e termos aparentemente fantasiosos, ou misteriosos, aparecem na parte inicial de Gênesis, a exemplo das duas formas do nome de Deus em Hebraico, uma no singular, Jeová, e uma outra no plural, Ahelohim. Ou quanto a estórias, como a que se refere a Chanoch, que passeou com Deus e desaparecendo; a referente a uma época de início da invocação de Deus; a uma época de aparecimento de gigantes sobre a superfície terrestre; ao cruzamento de filhos de Deus com as filhas do homem; etc. Comparando-se estas afirmações com as mais recentes descobertas arqueológicas, é possível afirmar que elas nos falam da convivência de homens sapiens com os homens de Neanderthal e que durou por cerca de $\mathbf{1 0 . 0 0 0}$ anos. Aproximadamente, entre há cerca de 35.000 a 25.000 anos. Conclui-se que, já há muito, o Velho Testamento vinha contando algo que ainda não era conhecido, o encontro sapiens/Neanderthal. Se a Bíblia nos parece que "nem sempre tem razão", por outro lado, ela pode "possuir razões que ainda não percebemos".

Palavras-chave: vocabulário e linguagem; "grandes narrativas"; Velho Testamento, arqueologia, encontro homo sapiens e homo Neanderthal. 
Introdução

0 trabalho se inicia com algumas idéias gerais sobre o tema da interpretação. 0 filósofo Emanuel Carneiro Leão lembra que o termo vem do Latim, inter, entre, e pretari, servir prestar. Interpretar "é fazer mediação entre pessoas e coisas, entre situações e criações". Lembra, também, que Goethe define a consistência da interpretação como sendo a de "levar a força criadora de uma realização para sua proveniência, na linguagem das línguas". No caso da música, por exemplo, a interpretação remete para a linguagem das escalas musicais. Na Geografia, um novo termo foi criado recentemente, geograficidade, que objetiva expressar a mediação que a Geografia realiza entre o mundo da materialidade geográfica e os processos sociais que dela participam, entre os quais, a cultura.

Depois de levantar questões teóricas e metodológicas relacionadas ao tema da re-interpretação, o presente trabalho trata de um estudo de caso, focalizando capítulos iniciais do Livro Gênesis, do Velho Testamento, que apresentam frases de sentido misterioso e fantasioso.

Finalmente, o trabalho retorna as reflexões teóricas, resultantes desta análise.

\section{Questões teóricas e metodológicas}

0 mundo se movimenta $e$ as linguagens também. Doreen Massey trata das relações entre as mudanças da formação econômica social e as mudanças de vocábulos e de formas de linguagem. Idéias teóricas que presidem o presente trabalho. Na era da História, além de se descrever e interpretar em forma escrita os fatos que foram acontecendo, tratou-se de recuperar o passado anterior, registrando-se em forma escrita, tudo que fora memorizado da tradição oral. A recuperação do quadro histórico de um passado profundo, anterior ao invento da escrita, passou a se valer, também, da análise de achados de objetos materiais produzidos naquele passado e dos sítios arqueológicos encontrados. Como se sabe, a tecnologia contemporânea oferece meios de se datar materiais que contenham carbono.

A instância ideológica faz parte de todas as produções realizadas, escritas ou orais. Contudo, há que separar instâncias ideológicas classificadas como negativas ou positivas, as primeiras se divorciando intencionalmente da busca da verdade, do real, atendendo a objetivos preconcebidos. Enquanto que as ideologias ditas positivas são inerentes a qualquer pensamento (KONDER, 2002). Assim, os produtores da História se dividem entre os que na sua descrição, ou na sua interpretação dos fatos, buscam estabelecer uma realidade verdadeira, e aqueles que praticam a História na esteira de seus interesses ideológicos. 0 que não impede que os primeiros também fiquem expostos ao cometimento de enganos. Há que mencionar, ainda, a categoria daqueles que transformam as suas fantasias 
poéticas imaginativas em fatos reais, identificados como arquétipos, ou mitos. A identificação deste quadro é um dos resultados obtidos pela prática necessária da re-interpretação, aplicável em todas as áreas do conhecimento. "O conhecimento consiste em reconstruir continuamente o objeto do conhecimento" (BACHELARD, 1973).

A narrativa relativa à produção material e à produção de idéias ao longo da história tem se valido de uma criação contínua de vocabulários e de estruturas e formas de linguagem. Ela compreende, também, a presença de conceitos associados aos termos que vão sendo criados. Uma vez estabelecida, a narrativa passa a ser sujeita a revisões criticas, quanto à veracidade dos fatos narrados, ou quanto aos conceitos embutidos em seus vocábulos. A diferença entre categoria e conceito e o relacionamento entre elas reside justamente neste fato.

Exemplificando: quando a Bíblia diz que Caim fundou uma cidade, ela introduz a categoria cidade. Este termo, esta categoria, associada a um pensamento lógico formal, atravessará os tempos históricos, a categoria cidade permanece nos dias atuais. Contudo, como seria esta cidade bíblica, certamente o ajuntamento de uma família expandida? Tal construção na atualidade não atenderia a um conceito atual de cidade. 0 conceito de cidade moveu-se ao longo do tempo, expressando uma lógica dialética. Os conceitos das coisas estão sujeitos a serem sempre renovados, ou, dito de outro modo, as coisas podem ser serem re-conceituados (LEFÈBRE, 1947).

No passado os termos surgiam na linguagem dos homens comuns e de suas elites intelectuais, poetas, contadores de histórias, profetas, filósofos. $\mathrm{Na}$ modernidade começaram a surgir termos produzidos pelas ciências. Os termos científicos também estão sujeitos a novas conceituações, porém, no caso das produzidas pela Física e Química, em um alcance infinitamente menor. Como exemplo de vocábulos e expressões criados na contemporaneidade, cita-se bóson, física quântica, inteligência artificial, globalização, países emergentes, indústrias criativas, soft power e tantas outras.

Como afirmado, a evolução dos vocabulários e das estruturas de linguagem é associada às transições históricas dos modos de produção e contribuem para a formação de novas subjetividades. "Vocabulários classificam e re-classificam os papéis, as identidades e os relacionamentos - de gentes, lugares, de instituições, e as práticas que as fazem incorporar" (MASSEY, 2013). A ampliação contínua do vocabulário, associada ao progresso científico e tecnológico, este último sendo particularmente acelerado na contemporaneidade, expressa a aproximação constante do conhecimento ao mundo real. 0 real, contudo, se apresenta sempre fugidio, inatingível, cada nova descoberta apresentando, novos questionamentos quanto à sua natureza.

Estas mudanças temporais das paisagens da linguagem possuem similaridade com as mudanças das paisagens nos espaços geográficos. Dada a esfericidade da Terra, o alcance visual 
de um observador na superfície do planeta é limitado pelo horizonte circular estabelecido em torno do seu ponto de observação. Além do horizonte outras paisagens podem estar presentes, e que podem envolver outras formas de adaptação de vida. A esfericidade da Terra é uma expressão da esfericidade do espaço/tempo. Do mesmo modo, horizontes de tempo separam formas da vida social atual, de formas vivenciadas no passado, inclusive no interior de um mesmo modo de produção. É comum novas gerações criarem seus dialetos próprios. Linguagens utilizadas no passado podem ser de difícil compreensão para os homens do presente, necessitando um esforço de interpretação. Quanto mais distante o tempo passado, mais difícil é a identificação dos homens presentes com as subjetividades vigentes naqueles tempos. Tema artisticamente explorado no filme Midnight Paris (WOODY ALLEN, 20012). Nesta história fictícia, um indivíduo é transportado da Paris atual para a Paris dos anos 20, e depois para a Paris da Belle Epoque. No entanto, torna-se difícil levá-lo, com a sua subjetividade contemporânea, para tempos mais recuados.

Dos novos vocábulos propostos em tempos recentes, cita-se particularmente a expressão "grande narrativa", criada por François Lyotard (LYOTARD, 1998). Ela é utilizada para designar um grande conjunto de escritos que, entre outras qualidades, tiveram um papel preponderante em moldar ideologias de longa permanência temporal e que exerceram e exercem papel central no curso da história da civilização. Também estas "grandes narrativas", com as suas ideologias, linguagens e vocabulários, se encontram expostas à re-interpretações e reformulações. É exemplo de "grande narrativa", o Capital e o conjunto de escritos relativos à teoria marxista, a proposta monoteísta do Velho Testamento (BRITISH and FOREIGN SOCTETY, 1921), as obras de Confúcio e de Platão, e outros.

\section{Re-interpretaçõees de textos do Velho Testamento}

Por que esta escolha do Velho Testamento, objeto, já, de tantas pesquisas arqueológicas e de linguagem por doutores eminentes? Porque se trata de uma oportunidade, a de cotejar descobertas arqueológicas muito recentes, fundadas em objetos materiais (cultura material) encontrados e que foram produzidos num passado muito remoto, com um vocabulário antigo que compreende termos aparentemente misteriosos e fantasiosos. A razão que move este propósito de expor estas comparações não é a de reafirmar a conhecida frase de que a "Bíblia tem sempre razão", mas, a de mostrar que, muitas vezes, ela tem razões das quais não se supunha.

A tradição judaica considera que o Velho Testamento foi primeiro texto redigido na forma escrita por Ezras e Nehemia, depois que parte da judeidade retornou do exílio na Babilônia, há uns 2.600 anos, por volta do século VI a.C. Segundo pesquisas arqueológicas, a primeira parte do Velho Testamento, o 
Pentateuco teria sido modelado no VII a.C. Note-se que estes séculos marcam um período de grande efervescência literária em todo o Mediterrâneo Oriental, incluídas as obras présocraticas dos filósofos da Ásia Menor. "Os filósofos são da Ásia Menor, a filosofia é grega”, estabelecem Gilles Deleuze e Félix Guattari, diferenciando a produção anterior de pensamentos filosóficos do aparecimento da conceituação de um campo denominado de Filosofia. (DELEUZE e GUATTARI, 1992).

Semelhanças podem ser encontradas comparando-se histórias de Homero com episódios narrados ns Bíblia. Por exemplo, no rapto e na recuperação de Helena, através do estratagema do cavalo de Tróia, e no rapto e na recuperação de Dina, pelo estratagema da circuncisão. Na cegueira dos ciclopes na libertação de Ulisses e na cegueira dos sodomitas no episódio da libertação dos mensageiros ameaçados na casa de Lot. A referência a um dilúvio aparece tanto em escritos da Bíblia, como na literatura grega (PLATÃO, 1946).

A ciência da natureza colocou em xeque a narrativa criacionista bíblica, quanto à origem do mundo, quanto à origem da espécie humana, e quanto a tantos outros fatos por ela mencionados. A Antropologia e o Freudismo introduziram os conceitos de mito e arquétipo, que presidem textos antigos produzidos por diferentes povos e de conteúdo semelhante. Por outro lado, fundados na diversidade das estruturas de linguagem contidas no texto, pesquisadores passaram a defender a idéia de que o Velho Testamento se constitui de uma compilação de diversos autores e de textos produzidos em diversas épocas. Os estudiosos da Antiguidade apontam, também, para o fato de que diversos eventos históricos citados na Bíblia, não encontram respaldo em outros documentos de mesma época. Por exemplo, a documentação em hieróglifos, deixados em pedra e em papiro da civilização egípcia, não menciona o êxodo dos servos israelitas para a Cananéia, nem registra estórias como a de José e Moisés. A narrativa da retirada, a salvo, de um recém nascido, como a de Moisés, de uma cesta flutuando nas águas de um rio, encontra paralelo em histórias semelhantes de outros povos da Antiguidade, e são tidas pela Antropologia como a repetição de um arquétipo, ou mito.

Fundado em raízes etimológicas, Freud considerou Moises como sendo um príncipe egípcio da linhagem do faraó Akenaton. Também considerou Jeová como sendo originariamente um Deus sanguinário de povos do deserto (FREUD, 1973). Contudo, como sugerido no título deste trabalho, qualquer idéia se encontra aberta para uma nova interpretação. Freud não conhecia o hebraico, nem era versado na tradição rabínica, não tendo percebido que YEOVAH, Jeová em hebraico, é um acrônimo de formas de futuro, presente e passado do verbo ser. Um Deus abstrato, identificado com o Ser. Ye é uma silaba de Yeheye, que significa será; Ov é sílaba de Ove, significando presente (Em hebraico não há a conjugação do presente do verbo ser; uma frase como "a menina é bonita" é dita como "a menina bonita"); e Ah é uma 
sílaba de Haiah, significando foi. Na Bíblia, quando Moisés indaga de Deus a quem deverá nomear como mandante, ao levar o projeto do êxodo, ante o Conselho dos Velhos do povo israelita, a resposta é "Serei o que serei" te envia (Êxodo, Capítulo 3,14). Esta narrativa aponta para a transição de um monoteísmo centrado em $\mathrm{Ra}$, o Sol, um ente material, para uma concepção abstrata fundada no tempo. Consagra intuitivamente a união espaço/tempo, matéria/espírito, um pilar da ideologia mosaica, que introduz a idéia da imanência a partir do mundo material. A idéia da imanência, centro da filosofia de Espinosa, aparece na segunda frases do Gênesis, "E a Terra era sem forma e em caos, e a escuridão cobria o abismo, e o sopro de Deus se movia sobre a superfície das águas" (Capítulo 1, versículo 2). A intensificação da pesquisa arqueológica na Israel/Palestina desde a instalação do Estado de Israel avolumou as críticas, fundadas na cultura material, à veracidade do apresentado na Bíblia (FINKELSTEIN e SILBERMAN, 2003). A composição de certas narrativas bíblicas teria sido elaborada com fins de justificativas ideológicas da época dos Reis (dos Profetas, na tradição judaica) colocando fatos em datas improváveis e estabelecendo relações de pura imaginação.

Sem a intenção de minimizar a validade arqueológica e da cultura material que trabalha com objetos produzidos no passado mais profundo, deseja-se evidenciar, também, a validade da técnica da re-interpretação dos vocábulos antigos para o conhecimento da história. 0 que pode inverter o julgamento, indicando que muitas informações da Bíblia, antes aparentemente fantasiosas e inverossímeis possuem foros de verdade. Como, por exemplo, na frase misteriosa que diz que um filho de Ever (14 ${ }^{\mathrm{a}}$ geração e 1.655 anos depois de Adão, pelas contas da Bíblia) foi denominado de Peleg porque na sua época as terras do mundo foram divididas por água. 0 nome de Peleg se refere certamente aos movimentos eustáticos do Pleistoceno e que separam continentes e povos.

Que ideologia levaria o texto bíblico a enumerar as gerações desde Adão, a idade dos antigos chefes de família ao terem o primeiro filho e anos completos de sua vida? A ideologia judaica tem, ao lado de outros, a guarda da memória como um dos seus mandamentos religiosos. Um outro é o de não mentir ("Não levantarás o meu Nome em vão"). 0 dia mais sagrado, o Yom Kippur, o Dia da Expiação, é também chamado no Velho Testamento como o Dia da Memória. Atualmente, nesse dia, quando os judeus religiosos rezam o dia inteiro na sinagoga, a afluência cresce para um momento solene, o da reza por familiares falecidos, o Yscor, a Lembrança. Ao longo do texto do Velho Testamento, repetidamente é dada esta ordem, a de guardar a memória, a lembrança. É que a ordem social é mantida pela preservação de princípios, sendo que "a história da ordem é a ordem da história" (VOEGLIN, 1958). Este seria o sentido do Velho Testamento, ao fornecer uma listagem de gerações desde Adão, informando a 
idade de cada chefe de família ao ter o seu primeiro filho, os seus anos totais de vida, cobrindo os séculos (a soma desde Adão até o nascimento de Abraão é de 1.846 anos). "A originalidade de Israel consiste em ser o primeiro a criar a história como forma de existência" (Idem).

Assim, a estrutura ideológica da crença judaica, valorizando a memória seria uma das motivações da forma de redação da Bíblia. Se muitas críticas podem ser feitas à sua veracidade, quer por intenções ideológicas quer por menor conhecimento, contudo, um caminho inverso também pode ser feito: o de descobrir realidades que a ciência moderna só recentemente vem anunciando. Através de expressões aparentemente fantasiosas, podem ser identificados fatos reais, como a separação entre os continentes pelo levantamento do nível do mar durante o Pleistoceno, ou a convivência do homo sapiens com o homem de Neanderthal.

0 culto à memória presente no Gênesis revela um pensamento voltado para o universal. As referências bíblicas aos patriarcas hebreus tratam de uma população organizada em clãs e seminômade. As populações que guardaram as ideologias bíblicas hebraicas mantiveram esta mobilidade e se espalharam pelo mundo inteiro. 0 ajuste dos judeus às culturas das terras em que habitam permanece como uma constante, atual, causando diferenciações culturais profundas entre a sua população tradicionalmente diaspórica. A palavra Torah, nome hebraico do Pentateuco significa literalmente conhecimento, e, portanto, o conhecimento se tornou através do credo judaico uma ideologia. São estas qualidades adquiridas pela ideologia judaica que se expressam no elevado número percentual de judeus envolvidos em teoria e prática política internacionalista, ou nas ciências naturais e sociais. Conhecida piada diz que inventaram a Lei, com Moisés, o Amor com Jesus, a Imanência divina com Espinosa, a Internacional, com Marx, o sexo com Freud e que, afinal tudo era relativo, com Einstein.

Marca histórica fortemente impressa na judeidade e presente no Velho Testamento resultou da relação dos israelitas com a civilização egípcia, cuja profundidade pode ser testemunhada por escritos gregos. A antiga historiografia escrita grega fala da dispersão diaspórica judaica, declarando "não haver nenhum lugar sem a sua presença". Fala, também, dos hábitos alimentares egípcios, e refere-se ao fato de que eles não utilizam pratos e talheres que não sejam próprios. Quando José se faz reconhecer aos seus irmãos e ordena lhes oferecer uma refeição, a Bíblia diz que serviram separadamente a José, aos irmãos e aos egípcios, "porque não podiam os egípcios comer com os hebreus, lhes seria abominável" (Capítulo 43, versículo 32). A Bíblia também narra que ao falecerem Jacó e José eles foram embalsamados, e descreve o embalsamento como sendo uma operação praticada por médicos, com duração de quarenta dias e abertura do corpo $(50,3)$. É lógico concluir que as atuais regras alimentares religiosas judaicas são heranças da cultura egípcia, com suas práticas de asseio. Até $\mathrm{o}$ presente $\mathrm{o}$ 
enterro judaico compreende a prévia lavagem interna do corpo desnudado numa capela.

A figura do faraó Memepetha, do século XIII a.C. aparece com uma Estrela no interior da qual se encontra inscrito Israel; e existe uma interpretação de que a mudança do nome de Jacó para Israel expressa um ajuste à cultura do Egito, o termo sendo uma contração dos termos RA, ISIS e EL. O signo de dois triângulos do escudo de David, emblema presente na bandeira do Estado de Israel, lembra a face da pirâmide. 0 triângulo é a primeira forma possível de se fechar um espaço com linhas retas. 0 espaço do Universo é curvo, e as formas da natureza são curvilíneas, enquanto que as linhas retas expressam a criação humana.

Se de um lado o passado se encontra aninhado no presente, por outro lado, é o presente que explica o passado. A narrativa bíblica conta que os irmãos de José não o reconhecem quando chamados ao palácio do faraó, mas, que ele, sim, os reconhece. Culturalmente transformado no Egito, José não é reconhecido pelos seus irmãos vindos do Canaã, mas, ele os reconhece, na lembrança do seu passado de juventude. Mais uma vez é confirmada a dialética de que, se o passado influi no presente, no entanto, é o presente quem explica o passado. Esta máxima foi aplicada na Geografia, quando, criticando teorias evolucionistas de de Martonne, Cailleux e Tricart introduziram a Geomorfologia Bioclimática fundada na observação de processos atuais.

\section{0 encontro do homo sapiens com o homem de Neanderthal}

Os primeiros capítulos de Gênesis apresentam uma série de frases e termos que solicitam explicações. 0 livro se inicia com a declaração que "no início Aelohim criou o Céu e a Terra". A designação im em hebraico é indicativa de plural, e há quem julgue que a referência a Aelohim é uma prova de um passado hebreu politeísta. Contudo, na língua hebraica fluídos não possuem a forma singular, apenas o plural. Não existe em hebraico a palavra água, ou céu, apenas águas, maim, e céus, shamaim. Deus é descrito como imanente, fluido (presente em toda parte), A frase citada pode ser considerada como uma combinação da idéia criacionista com a idéia da filosofia grega de que nada é criado do nada. $\mathrm{Na}$ teoria do big bang, o Universo foi criado da explosão de uma Singularidade, um corpo de dimensões infinitamente mínimas e de uma alta densidade inimaginável. Já recentemente surgiu a teoria do Universo como um gigantesco computador quântico (VERDAL, 2010), sugerindo a precedência da informação. Novamente, a combinação de matéria e criação.

Em todo o primeiro capítulo de Gênesis, 31 versículos, o nome de Deus só aparece na forma Aelohim. Termo composto de Ael, O Ele, e a designação do plural hoim, Os Eles. Somente no segundo capítulo aparece o nome Yeovah, que é pronunciado pelos judeus como Adonai, (Meu Senhor), pois, que, lhes é proibido pronunciar o acrônimo. 
(Ao final das orações do Yom Kippur, as assembléias nas sinagogas bradam sete vezes que "Aelohim é o Yeovah!").

No Capítulo 4,26 se diz que no tempo de Enosh, neto de Adão, "os homens passaram a invocar o nome de Deus".

Logo em seguida, no Capítulo 5, 22, 24, é dito que Chanoch, sétima geração, sai para passear com Aelohim e desaparece.

O Capítulo 6, 1 diz que "E passa que o homem se multiplica na face da Terra e filhos lhe nascem".

No Capítulo 6, 2: "E os filhos de Aelohim viram que as filhas do homem eram agradáveis e tomaram como esposas todas que escolheram. Deus decide que a vida do homem é de 120 anos".

Capítulo 6, 6: "Havia gigantes naquele tempo":

0 que o conjunto destas frases nos conta? Certamente, o que está sendo contado versa sobre o encontro do homo sapiens com o homem de Neanderthal.

Uma das recentes novidades científicas baseadas na arqueologia é a evidência de uns 10.000 anos de convivência do homo sapiens com o homem de Neanderthal. Isto teria ocorrido entre cerca de 35.000 e 25.000 anos atrás, no Oriente Médio e na Europa, depois que o sapiens saiu da África, sua região de origem. 0 leitor poderá encontrar farta matéria sobre o tema na conhecida Revista Science, da American Association for the Advancement of Science (por exemplo, em GIBBONS, 2014, e em VERNOT e AKAY, 2014), sendo que memória destes encontros estaria registrada na Bíblia.

A referência a que, durante a época de Enosh, se passou a invocar o nome de Deus deve significar o aparecimento mais refinado da religião como idéia, produzida certamente pelo sapiens, de cultura mais avançada. Ou/e que, até aquela época, os sapiens eram vistos como deuses pelo Neanderthal. Lembre-se que, quando a cavalaria espanhola foi vista pela primeira vez pelos Astecas, eles tomaram homem e cavalo como sendo um só. Ou que Caramuru foi endeusado pelos índios por tocar fogo em álcool que eles supunham ser água. Assim, quando é dito que Hanoch foi passear com Aelohim, significa que o primeiro, Neanderthal, saiu com um sapiens.

Resultam duas conclusões. Primeiro: Adão e seus descendentes eram da espécie Neanderthal. Segundo, que o plural de Aelohim pode ser atribuído também ao fato de representar os sapiens, que aparecem como deuses para os primeiros. Assim, quando no Yom Kippur se brada sete vezes que Adonai hu Aelohim, que Deus é Aelohim, é porque os antigos sábios já perceberam as complicações deixadas pelo texto bíblico.

A frase do Capitulo 6, 1 falando da multiplicação do homem não se refere certamente à simples reprodução natural, já indicada no "crescei e multiplicai" de uma passagem anterior. Ela pode indicar dois fatos: a de que surgiu a nova espécie, a sapiens, e/ou que a nova espécie possuía maior taxa de crescimento. Realmente, as teorias antropológicas fundadas na arqueologia apontam para a alimentação mais rica em proteína do sapiens, e que permitiria maiores densidades. 
Inicialmente o sapiens é caçador, inclusive de mamutes, com o auxílio do cão que ele domesticou e com o qual aprendeu a se comunicar até pelo olhar. Quanto à citação de gigantes havidos no passado, seria uma outra referência aos sapiens, de estatura mais alta. A narrativa bíblica inicial parece assim ser ditada por uma tradição oral proveniente do Neandarthal. Ou seja, a linguagem da Bíblia se alterna, ora partindo de uma, ora partindo de outra das duas espécies coexistentes num passado remoto. Conflitos, mestiçagens, e menor defesa ante as feras, teriam levado à extinção do Neandarthal.

Apesar de esta espécie ter sido mais selvagem, seus indivíduos poderiam atingir maior longevidade, enquanto cento e vinte anos seria o limite do sapiens. Assim se explicaria as centenas de anos de vida atribuídas às gerações de Adão.

A narrativa dos filhos de Deus que cruzam com as filhas do homem seria a narrativa do cruzamento das duas espécies humanas na maior profundidade do passado.

\section{Conclusão}

No trabalho sobre a origem da obra de arte, Heidegger, elabora uma teia de idéias filosóficas, a partir da análise de um quadro de botas de camponês pintadas por Van Gogh, observando a miríade de articulações que a "coisa" sugere, com toda a vida social (HEIDEGGER, 2006). Arte e Articulação compartilham do mesmo radical.

A articulação de todas as instâncias sociais e a negação de um fator único, ou de fatores, na condução da história é também uma premissa Marxista. A instalação de um modo de produção decorre dos inúmeros intercâmbios promovidos pelo mesmo no tecido social e de suas difusões espaciais e temporais (MARX e ENGELS, 1996).

A re-interpretação compreende esta ação de articulação, ela compreende a busca de relações entre diversas fontes, a introdução de novos componentes nas "coisas" sob análise. No estudo de caso e objeto do presente trabalho, foram expostas observações pertinentes ao vocabulário utilizado nos primeiros capítulos do Gênesis, que conduzem à maior conhecimento de trechos da Bíblia. Estes acréscimos não desmentem as críticas sobre equívocos presentes no texto bíblico, ou a afirmação de que, muitas vezes, a Bíblia "não tem razão" Porém, por outro lado, crê-se que o presente estudo mostra que é possível descobrir que há "outras razões" no Velho Testamento que não eram conhecidas.

\section{Notas}

1 Instituto de Geografia, UERJ. Bolsista Sênior do CNPq, como Professor Doutor. Email: pedro.geiger@gmail.com

\section{Referências Bibliográficas}

ALLEN, Woody, Midnight in Paris, Gravier Productions, 2011. 
BACHELARD, Gaston, A Filosofia do Não e outros textos, São Paulo, Abril, 1973.

BRITISH and FOREIGN SOCIETY, THE OLD TESTAMENT, Hebrew and English, Londres, 1921.

CARNEIRO LEÃO, Emmanuel, O que é a Interpretação, Conferência no ciclo de Conferências 0 Problema da Interpretação, ABL, 02/092014.

DELEUZE, Gilles, e GUATTARI, Félix, 0 que é a filosofia. Rio de Janeiro, editora 34, 1992.

FINKELSTEIN, L, e SILBERMAN, N.A., A Bíblia Não Tinha Razão, São Paulo, A Girafa, 2003.

FREUD, Sigmund, Moisés e o Monoteísmo, Obras Completas, V. 23, Rio de Janeiro, Imago, 1973.

GIBBONS, Ann, Neanderthal and Modern made Imperfect Mates, Science, 343-617 / 471-472, 2014.

KONDER, Leandro, A Questão da Ideologia, São Paulo, Companhia das Letras. 2002.

LEFÈBVRE, Henri, Logique Formel, Logique Dialectique, Paris, Éditions Sociales, 1947

LYOTARD, Jean François, A condição pósmoderna, Rio de Janeiro, editora 34, 1998.

MARX, Karl, e ENGELS, Frederic, A
Ideologia Alemã (Feuerbach), São Paulo, HUCITEC, 1996.

MASSEY, Doreen, Chapter 2, Vocabularies of the Economy, in, Stuart Hall, Doreen Massey and Michal Rustin, editors, After Neoliberalism? The Kilburn Manifesto, London, Lawrence \& Wisharj, 2013.

PlATÃo, Ouevres Completes, Tome Sixiéme, LES LOIS, (Livres I-VI), Paris, Librairie Garnier Fréres, 1946.

VERDAL, Vlatko, Decoding Reality. The Universe as Quantum Information, Oxford, Oxford University Press, 2019.

VERNOT, Benjamin, e AKEY, Joshua M, Resurrecting Surviving Neanderthal Lineage from Modern Human Genomes, Science, 343-6174:1017-1021, 2014.

VOEGLING, Eric, Israel and Revelation, Volume I, Order and History, Baton Rouge, Louisiana State University Press, 1958. 


\section{REINTERPRET ALWAYS AND THE HORIZONS OF HISTORY}

ABSTRACT: FOLLOWING THE TRANSITIONS OF THE HISTORICAL MODES OF PRODUCTION, THE LANGUAGES AND THE VOCABULARIES DID CHANGE THEIR MEANINGS AND THEIR STRUCTURE. ONE TAKES A "GREAT NARRATIVE" AS A CASE STUDY, THE BOOK OF GENESIS, A COLLECTION OF ORAL MEMORIES ORIGINATED FROM THE MORE DEEP TIMES. COMPARING RECENT ARCHEOLOGICAL DISCOVERIES WITH THE BIBLICAL LANGUAGE OF OLD WORDS, ONE CONTRIBUTES TO A LARGER UNDERSTANDING OF HISTORICAL DEVELOPMENTS IN PAT ABYSSAL TIMES. THUS, ONE FOLLOWS THE PRINCIPLE THAT SAYS THAT "IT IS THE PRESENT THAT EXPLAINS THE PAST".

IN ITS FIRST CHAPTERS THE BOOK PRESENTS MYSTERIOUS AND STRANGE EXPRESSIONS AND PERIODS, AS ABOUT TWO DIFFERENT NAMES FOR GOD, ONE IN A SINGULAR FORM, AND ANOTHER IN PLURAL. STORIES LIKE ABOUT CHANOCH, WHO WENT TO WALK WITH GOD AND DISAPPEARED; ABOUT TIMES WHEN THE NAME OF GOD STARTED TO BE EVOKED; OR ABOUT GIANTS ON THE EARTH SURFACE. OR TELLING ABOUT SONS OF GOD HAVING INTERCOURSES WITH THE MEN 'S DAUGHTERS AND SO ON. ONE COMPARES THESE STATEMENTS WITH THE ARCHEOLOGICAL PROOFS ABOUT A PAST CO-EXISTENCE OF THE HOMO SAPIENS WITH THE HOMO OF NEANDERTHAL FOR ABOUT 10,000 YEARS, DURING THE ALMOST PAST 35,000 AND 25,000 YEARS. ONE CONCLUDES THAT, FOR LONG, THE OLD TESTAMENT WAS TELLING US THING WE DID NOT PERCEIVE, AS THIS SAPIENS/NEANDERTHAL ENCOUNTER. IF, IN MANY OCCASIONS, THE BIBLE SEEMS "NOT HAVING REASON", IT MAY HAPPEN THAT IN OTHER OCCASIONS "IT HAS REASONS NOT PERCEIVED YET".

KEYWORDS: VOCABULARY AND LANGUAGE; "GREAT NARRATIVES": THE OLD TESTAMENT, ARCHEOLOGY, SAPIENS AND NEANDERTHAL ENCOUNTER. 


\section{RÉINTERPRÉTER TOUJOURS ET LES HORIZONS DE L'HISTOIRE}

RESUMÉE: LANGUAGE ET VOCABULAIRE CHANGENT AU LONG DU TEMPS, ILS ACCOMPAGNENT LES TRANSITIONS DES MODES DE PRODUCTION. AVEC LA REINTÉRPRETATION DES CONCEPTS DE MOTS ANTIQUES, EN LIGNE AVEC LES DÉCUVERTES ARCHÉOLOGIQUES, ET SUIVANT LE PRINCIPE QUE C'EST LE PRESENT QUI EXPLIQUE LE PASSÉ, IL EST POSSIBLE DE CONTRIBUER A UNE COMPREHENSION PLUS GRANDE DES DEVELLOPMENTS HISTORIQUES QUE SE SONT PASSEÉ DANS UN TEMPS TRÉS PROFUNDS. DANS CE SENS, ON REALISE UN « ÉTUDE DE CAS », AYANT COMME OBJET, " UNE GRANDE NARRATIVE », LE GENÈSIS. CE LIVRE SERAIT UNE COLLECTION DE MÉMOIRES ORAAUX VENNANTS DU TEMPS PLUS PROFONDS.

LA COMMENCEMENT DE GENĖESIS PRESENT DES MOTS ET DES PHRASES APPARENTEMENT FANTASTIQUES OU MYSTERIEEX. PAR EXAMPLE, LES DEUX FORMES DU NOM DE DIEU, UNE AU SIGULIER, L'AUTRE AU PLUREIL ; OU DES HISTOIRS, COMME CELLE DE CHANOCH, QUI SORT « POUR SE PROMMENER AVEC DIEU ET DISPARAIT » ; LA REFEÉRÉNCE A UNE ÉPOQUE QUAND LE NOM DE DIEU. A COMMENCÉ A ÊTRE INVOQUÉ OU, ENCORE, QUAND LE LIVRE RACONTE SUR LES GÉANTS SUR LA FACE DE LATERRE, OU QUE LES FILS DE DIEU ONT PRIS LES FILLES DU HOMME POR ÉPOUSES, ETC. EN FAISANT UNE COMPARAISON DE CES ÉCRITS AVEC DES DERNIÉRES DÉCOUVERTES ARCHÉOLOGIQUES, QUI DEMONTRENT LA CO-EXISTENCE DU HOMO SAPIENS AVEC LE HOMO DE NEENDARTHAL, DURANT, PROCHAINEMENT, 10,000 ANNÉES, IL Y A 35.000 A 25.000 ANS, ON ARRIVE À LA CONCLUSION QUE, IL Y A DEJÁ LONG TEMPS QUE LE VIEUX TESTAMENT NOS RACONTE DES CHOSES QUE N'ONT ÊTE ENCORE PERÇU. SI IL EST VRAIS QUE LA BIBLE N'A PAS RAISON TOUJORS, D’OUTRE COTÊ, « ELLE PEUT AVOIR DES RAISONS PAS ENCORE PERÇU ».

MOTS-CLÉ: VOCABULAIRE ET LANGUAGE, “GRANDES NARRATIVES", LE VIEUX TESTAMENT, ARCHÉOLOGIE, LE SPIENS ET LE NEENDARTHAL RANCONTRE ;. 